\title{
Advocating Evidence Based Health Promotion in Physiotherapy
}

\begin{abstract}
There has been a significant acceleration in the development of health promotion in Africa over the last 20 years. Health promotion is a practical approach to achieving greater equity in health. It has thus become an essential component of health delivery for all health professionals. Health promotion strategies can develop and change lifestyles as well as have an impact on the social, economic and environmental conditions that determine health. The most

Frantz JM, PhD'

1 Departmental Chairperson, Department of Physiotherapy, University of the Western Cape. visible challenge for health promotion development in Africa is the fact that people only passively participate in the health promotion process. Health professionals such as doctors and nurse control the majority of the programmes and the question remains: "What is the role of Physiotherapy in health promotion?" This paper thus aims to highlight and recommend the role of Physiotherapy in evidence-based health promotion
\end{abstract}

\section{KEY WORDS: PHYSIOTHERAPY, EVIDENCE, HEALTH PROMOTION.}

\section{INTRODUCTION:}

Health promotion is a concept that is frequently used among health professionals. It is considered a multifactor process operating in individuals and communities, through education, prevention, and protection measures (Tannahill, 1985). The broad definition commonly used is that health promotion is "the process of enabling people to increase control over their health and to improve it." (WHO, 1986). According to Nyamwaya (2003) there has been a significant acceleration in the development of health promotion in Africa over the last 20 years. Health promotion is a practical approach aimed at achieving greater equity in health. Health promotion strategies can develop and change lifestyles as well as have an impact on the social, economic and environmental conditions that determine health. The five strategies set out in the Ottawa Charter for health promotion are essential for success and these include:

\section{CORRESPONDENCE TO:}

\section{Professor JM Frantz}

Department of Physiotherapy

University of the Western Cape

Private Bag X17

Bellville

7530

Tel: 2721 959-2542

Fax: 2721 959-1217

E-mail: jfrantz@uwc.ac.za
1. building healthy public policy

2. creating supportive environments

3. strengthening community action

4. developing personal skills

5. re-orienting health services

According to the Ottawa Charter, health promotion is defined as the "process of enabling people to exert control over the determinants of health and thereby improve their health. Physiotherapists can play a role in all five areas identified by the Ottawa Charter.

Nutbeam (1998) stated that health promotion is not something that is done on or to people but it is something that is done with people. The emergence of diseases such as AIDS and chronic diseases of lifestyle has taught us the importance of remaining vigilant in our public health and health promotion efforts relating to the well-being of our population as these are diseases mainly influenced by risky behaviour and can be prevented. Health is a basic human right and is essential for social and economic development. Potter (1998) stated that changing disease patterns and increased pressures on health care services have important implications for health promotion. Thus as the pressure increases on health care services, the need for effective implementation and evaluation of health promotion programmes arises. The purpose of this paper is to highlight the role that physio- therapists can play in the promotion of health promotion programmes and ensuring that it is evidence based.

\section{HEALTH PROMOTION PROGRAMMES}

In 2003, according to the International Union for Health Promotion and Education (IUHPE), the following operational plan was developed for the African Region regarding health promotion programmes:

- developing and disseminating guidelines on assessment of health promotion programmes

- conducting an effective literature review on effectiveness of health promotion programmes in the region

- implementing special research projects regarding topics such as tobacco, youth/adolescent health, ageing, CDL)

- commissioning a publication to review and synthesize evidencebased health promotion effectiveness (Anonymous, 2004)

According to Nyamwaya (2003), the most visible challenge for health promotion development in Africa is the fact the public or people only passively participate in the health promotion process. The majority of programmes are controlled by health professionals such as doctors and nurses even though health promotion activities have become a fundamental requirement for all health professionals. This raises the question: "What is the role of evidence based physiotherapy in health promotion?" 
As health care providers, physiotherapists are in an ideal position to address health promotion issues (Higgs et al 2001). .

\section{EVIDENCE-BASED HEALTH PROMOTION - THE FIRST CHALLENGE}

In many cases physiotherapists believe that the success of an intervention needs to be scientifically based to demonstrate its effectiveness but how is this evidence to be obtained? The lack of support for evidence based health promotion activities could have a negative effect on implementation of evidence based policy efforts (McQueen 2001), especially in the area of physiotherapy.

Turner (2001) indicated that at that time physiotherapy had a weak research evidence base and highlighted the need for the physiotherapy profession to monitor growth of evidence for the profession.

According to McQueen (2001), health promotion will fall or rise based on its ability to demonstrate in a scientific way that is an effective field. The World Health Assembly (1998) stated that health promotion practitioners and researchers should base their work on evidence. Evidence-based medicine has been defined as the use of the current best evidence namely individual clinical expertise and external clinical practice, in making decisions about the care of individual patients (Sackett, Rosenberg, Gray, Haynes and Richardson, 1996). Even though evidence based medicine has been applied to mainly clinical decision making, the concept could be expanded to include other aspects of health care decision making e.g. the selection of health promotion programmes. According to Rada, Ratima and Howden-Chapman (1999), evidencebased health promotion is an approach to practicing health promotion in which the health care provider and client are aware of the evidence supporting selected strategies and the strength of that evidence. Speller et al (1997) stated that the effect of health promotion activities should be assessed across the breadth of its activities and settings, and not just by changes in individual health behaviour. The authors further stated that systematic review methods need to be revised in order to be able to include a broader range of studies and research methods, including qualitative research. Thus Rychetnik and Wise (2004) identified the types of evidence that may be sought to support evidence-based health promotion:

1. evidence on the magnitude and aetiology of health problems

2. evidence on the effectiveness of local health promotion interventions

3. evidence of the impact of public policy initiatives or the dissemination of programs to larger populations

4. evidence of cost-effectiveness of initiatives

\section{MEASURING THE OUTCOME - ANOTHER CHALLENGE FOR HEALTH PROMOTION PROGRAMS}

The lack of evidence for intervention to promote health is not the only challenge facing health promotion. The problem of lack of indicators for measuring health promotion effectiveness especially among physiotherapists is another challenge for successful health promotion programmes. According to Mc Queen (2001), it is highlighted that evidence based health promotion is at a critical point for not only public health specialists but for other health professionals as well. McQueen (2001) further highlighted that many health disciplines produce standards for evidence-based practice and many of these standards have been adapted in health promotion practice. However, McQueen (2001) states that the field of health promotion is too broad to be limited by evidence standards derived from elsewhere. Health promotion needs to foster and develop high quality, widely recognized and acceptable standards for evidence based evaluation. The range of strategies employed in health promotion and the different outcomes for each strategy implies that there is the potential for a wide range of indicators that needs to be considered.

According to Rychetnik and Wise (2004), evidence refers primarily to information derived from evaluation research that has assessed the effects and outcomes of potential interventions. The important aspect is to focus on health promotion outcomes. Nutbeam (1998) stated that health promotion outcomes should reflect modification to those personal, social and environmental factors, which are a means of improving people's control and thereby changing the determinants of health. Thus health promotion activities should have outcomes that are set by all key stakeholders to avoid outcomes being seen as negative. According to Whitehead (2004), outcomes can be positive and negative. A positive outcome relies on the capacity of communities and individuals within communities to become politically and socially empowered, so that they can prioritize and act upon health promotion issues based on local need. The author further states that a negative outcome occurs when health professionals enforce disempowering health policy decisions on a community that are not based on the needs of the community.

Nutbeam (1998) indicated that criteria for evaluating the success of health promotion programmes should include factors such as:

- programme reach (did the programme reach the target population?),

- programme acceptability and

- programme integrity.

The greatest strength of health promotion is that it cuts across sectors and various disciplines. However, many of these traditional disciplines have produced their standards for evidence-based practice. Thus the challenge for health promotion is to foster and develop high quality and acceptable standards for evidencebased health promotion and physiotherapy should form part of this process.

According to Rapheal (2000), enough evidence is available to justify health promotion as a discipline that can improve the health of the population. The author suggests the following guidelines for making decisions and using evidence in health promotion:

- Be explicit as possible regarding the principles and values regarding your health promotion activities

- Recognize the tensions and interaction between structural and individual determinants of health and between values and facts

- Use multiple sources of evidence

- Show awareness of the decisions you make concerning the evidence: be a reflective practitioner 
Table 1: Quality criteria for health promotion programmes

\begin{tabular}{|l|l|l|l|l|}
\hline Indicators & $\begin{array}{l}\text { Programmes } \\
\text { Outcomes }\end{array}$ & $\begin{array}{l}\text { Programmes } \\
\text { Process }\end{array}$ & $\begin{array}{l}\text { Research } \\
\text { Designs }\end{array}$ & Repeatability \\
\hline Goals of the programme & Knowledge changes & Networking & Participatory research & Is it universal? \\
\hline Selected target groups & Environmental changes & Commitment & Action research & Is it limited? \\
\hline $\begin{array}{l}\text { Division of responsibility } \\
\text { at management and } \\
\text { operational level }\end{array}$ & $\begin{array}{l}\text { Epidemiological } \\
\text { changes }\end{array}$ & Exposure & $\begin{array}{l}\text { Qualitative } \\
\text { research }\end{array}$ & \\
\hline Resources & Behavioral changes & Participation & & \\
\hline Organization & Maintenance & & & \\
\hline
\end{tabular}

\section{PHYSIOTHERAPY IN EVIDENCE-BASED HEALTH PROMOTION}

According to Rea et al (2004), physiotherapists are addressing health promotion topics with patients but are these topics and programmes being evaluated and meeting the basic guidelines suggested for evidence-based health promotion? Within the physiotherapy profession there is a need to agree on criteria for effectiveness and quality of health promotion programmes. As health promotion programmes conducted by physiotherapists take place in a variety of settings such as communities, workplace and schools the criteria for effectiveness should be clearly defined and based on clear outcomes. Aro, van den Broucke and Räty (2005), concluded that success in evidence based health promotion is dependent on how the gap between research and practice is bridged.

Based on all the information presented and information from Tang, Ehsani and McQueen (2003); Ader, Berensson, Carlsson, Granath and Urwitz (2001) and Koelen, Vaandrager and Colomér (2001), the author would like to suggest that physiotherapists consider the following information when designing and implementing health promotion programmes as quality indicators (Table 1).

A typical example that can be used in South Africa is back week. This is a national intervention programme targeting a large population group of all ages. However, the effectiveness of this national programme has not been evaluated. Using the recommended outcomes the South African Society of Physiotherapy (SASP) should consider evaluating the back week programme according to knowledge, environmental and behavioral changes. The results of such a study would impact on physio- therapists and physiotherapy students as it is the one big event in which all universities participate. The events highlighted in the physioforum are evidence that excellent programmes are being implemented but we should provide therapists and students with the information to be able to evaluate the effectiveness of these programmes.

\section{CONCLUSION}

The inclusion of health promotion programmes by physiotherapists in the management of patients is universal. However, effective evaluation of these programmes has been hindered by lack of outcome measures for these health promotion programmes. The author hopes that the article will offer physiotherapists a basis for indicators when implementing health promotion programmes.

\section{REFERENCES:}

Ader M, Berensson K, Carlsson P, Granath M and Urwitz V (2001). Quality indicators for health promotion programmes. Health Promotion International. 16(2): 187-195.

Anonymous (2004). Global health promotion and health education initiatives: an update and what...Promotion and Education 11(4): 213-217

Aro A, Van den Broucke S and Räty S (2005). Toward European consensus tools for revewing the evidence and enhancing the quality of health promotion practice. Promotion and Education. 10-14.

Higgs J, Refshauge K, Ellis E (2001). Portrait of the physiotherapy profession. Journal of Interprofessional Care. 15(1): 79-89.

Koelen M, Vaandrager L and Colomér C (2001). Health promotion research: dilemmas and challenges. Journal of Epidemiological Community Health 55: 257-262.

McQueen D (2001). Strengthening the evidence of health promotion. Health Promotion International. 16(3): 261-268.

Nutbeam D (1998). Evaluating health promotion - progress, problems and solutions. Health Promotion International. 13(1): 27-48.
Nyamwaya D (2003). Health promotion in Africa: strategies, players, challenges and prospects. Health Promotion International 18(2): 85- 87.

Potter I (1998). Looking back, looking ahead health promotion: a global challenge. Health promotion International 12(4): 273-277.

Rada J, Ratima M, Howden-Chapman P (1999). Evidence based purchasing of health promotion: methodology for reviewing evidence. Health Promotion International. 14(2): 177-187.

Raphael D (2000). The question of evidence in health promotion. Health Promotion International. 15(4): 355-367

Rea B, Marshak H, Neish C, Davis N (2004). The role of health promotion in physical therapy in California, New York and Tennessee. Physical Therapy 84(6): 510-523.

Rychetnik L and Wise M (2004). Advocating evidence-based health promotion: reflections and a way forward. Health Promotion International. 19(2): 247-257.

Sackett D, Rosenberg W, Gray J, Haynes R and Richardson W (1996). Evidence based medicine: what it is and what it isn't. British Medical Journal 312: 71-72.

Speller V, Learmonth A and Harrison D (1997). The search for evidence of effective health promotion. British Medical Journal. 315: 361-363.

Tang K, Ehsani J and McQueen D (2003). Evidence based health promotion: recollections, reflections and reconsiderations. Journal of Epidemiological Community Health. 57: 841-843.

Tannahill A (1985). What is health promotion? Health Education Journal 44: 167-168.

Turner P (2001). Evidence based practice and physiotherapy in the 1990's. Physiotherapy Theory and Practice 17(2): 107-121.

Whitehead D (2005) Health promotion and health education: advancing the concepts. Journal of Advanced Nursing 47(3): 311-320. World Health Assembly (1998). World Health Assembly Resolution: Health Promotion. WHA 51, 12. 16 May 1998.

World Health Organisation (1986). The Ottawa Charter: principles for health promotion. Copenhagen: WHO Regional Office for Europe. 